\title{
Can we evaluate population screening strategies in UK general practice? A pilot randomised controlled trial comparing postal and opportunistic screening for genital chlamydial infection
}

\author{
Abiola Senok, Phil Wilson, Margaret Reid, Anne Scoular, Neil Craig, Alex McConnachie, Bridie \\ Fitzpatrick, Alison MacDonald
}

J Epidemiol Community Health 2005;59:198-204. doi: 10.1136/jech.2004.021584

See end of article for authors' affiliations

Correspondence to Dr P Wilson, General

Practice and Primary Care, Division of Community Based Sciences, University of Glasgow, 1 Horselethill Road, Glasgow G12 9LX, UK; p.wilson@clinmed.gla. ac.uk

Accepted for publication 9 July 2004

\begin{abstract}
Study objective: To assess whether opportunistic and postal screening strategies for Chlamydia trachomatis can be compared with usual care in a randomised trial in general practice.

Design: Feasibility study for a randomised controlled trial.

Setting: Three West of Scotland general medical practices: one rural, one urban/deprived, and one urban/affluent.

Participants: 600 women aged 16-30 years, 200 from each of three participating practices selected at random from a sample of West of Scotland practices that had expressed interest in the study. The women could opt out of the study. Those who did not were randomly assigned to one of three groups: postal screening, opportunistic screening, or usual care.

Results: $38 \%$ (85 of 221) of the approached practices expressed interest in the study. Data were collected successfully from the three participating practices. There were considerable workload implications for staff. Altogether 124 of the 600 women opted out of the study. During the four month study period, $55 \%$ (81 of 146) of the control group attended their practice but none was offered screening. Some $59 \%$ (80 of 136) women in the opportunistic group attended their practice of whom 55\% (44 of 80) were offered screening. Of those, $64 \%$ (28 of 44 ) accepted, representing $21 \%$ of the opportunistic group. Forty eight per cent $(59$ of 124) of the postal group returned samples.

Conclusion: A randomised controlled trial comparing postal and opportunistic screening for chlamydial infection in general practice is feasible, although resource intensive. There may be problems with generalising from screening trials in which patients may opt out from the offer of screening.
\end{abstract}

There are no published trials comparing postal with opportunistic screening for genital chlamydial infection. This feasibility study sought to establish the practical considerations for implementing a successful randomised controlled trial (RCT) of active screening strategies for genital chlamydial infection in general practice.

\section{METHODS \\ The practices}

We invited 221 West of Scotland general medical practices to participate. Practices were given details of the work involved and of financial reimbursement (at hourly rates corresponding to normal salaries, with overtime paid at 50\% above standard rates). Using postcodes, practices agreeing to participate were stratified by location and deprivation into three types (rural, deprived urban, and affluent urban). We classified deprivation categories 1 and 2 as affluent and categories 6 and 7 as deprived. ${ }^{16}{ }^{17}$ One from each type was chosen at random to participate.

In-practice training was organised for clinical and clerical staff. A three day course for practice nurses was provided by a sexual health advisor and three of the authors. Course content included clinical features and management of chlamydia and other sexually transmitted infections; counselling; giving a positive result and partner notification.

Ethics and data protection

Three local research ethics committees (LRECs) granted ethics approval. The first LREC we approached insisted that women over 20 years, a much lower risk population than teenagers. ${ }^{1}$ 


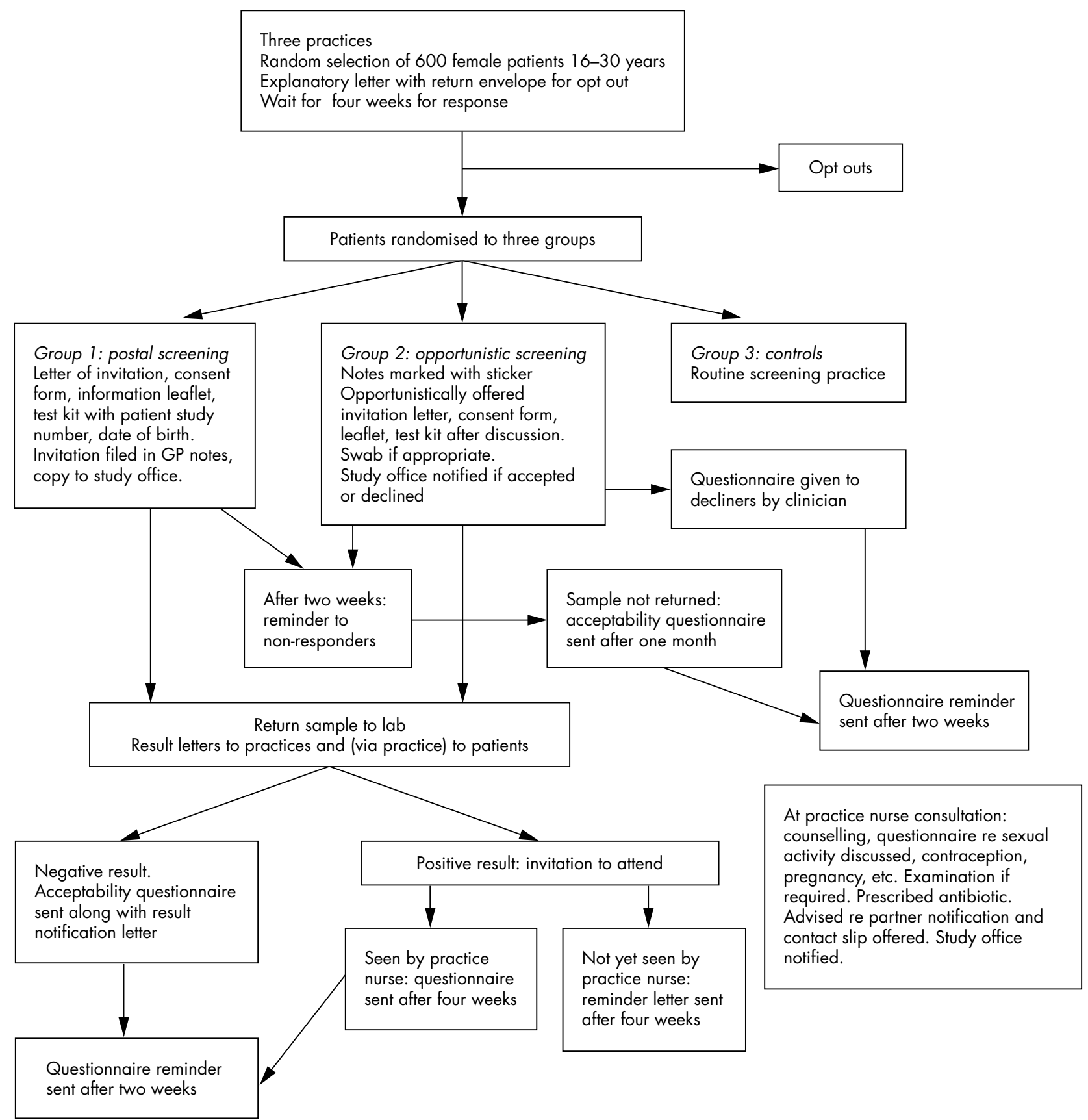

End of study: peruse all GP notes for lab results, data on sexually transmitted infections, pregnancies, contraception, etc in study period and preceding year

Figure 1 Study protocol.

some form of consent from participants was required. Women were sent an introductory letter describing the study and indicating that participation might entail receiving chlamydia test kits, questionnaires, and data extraction from their records. The option to opt out was offered at this stage. In two practices, women opting out were informed that information about postcode sector and year of birth would be collected. In the third practice, the LREC required patients to have the choice of opting out without this information being used. Patients who had not been sexually active were not asked to opt, but the introductory letter explained that chlamydial infection was sexually transmitted. Women returning samples or questionnaires were asked to provide written consent.

\section{Intervention phase (June-September 2002)}

Figure 1 summarises the study protocol. Practice staff were given a procedure manual and continued support from the researcher by phone calls, emails, and visits. They were provided with templates for standard letters to be signed by 


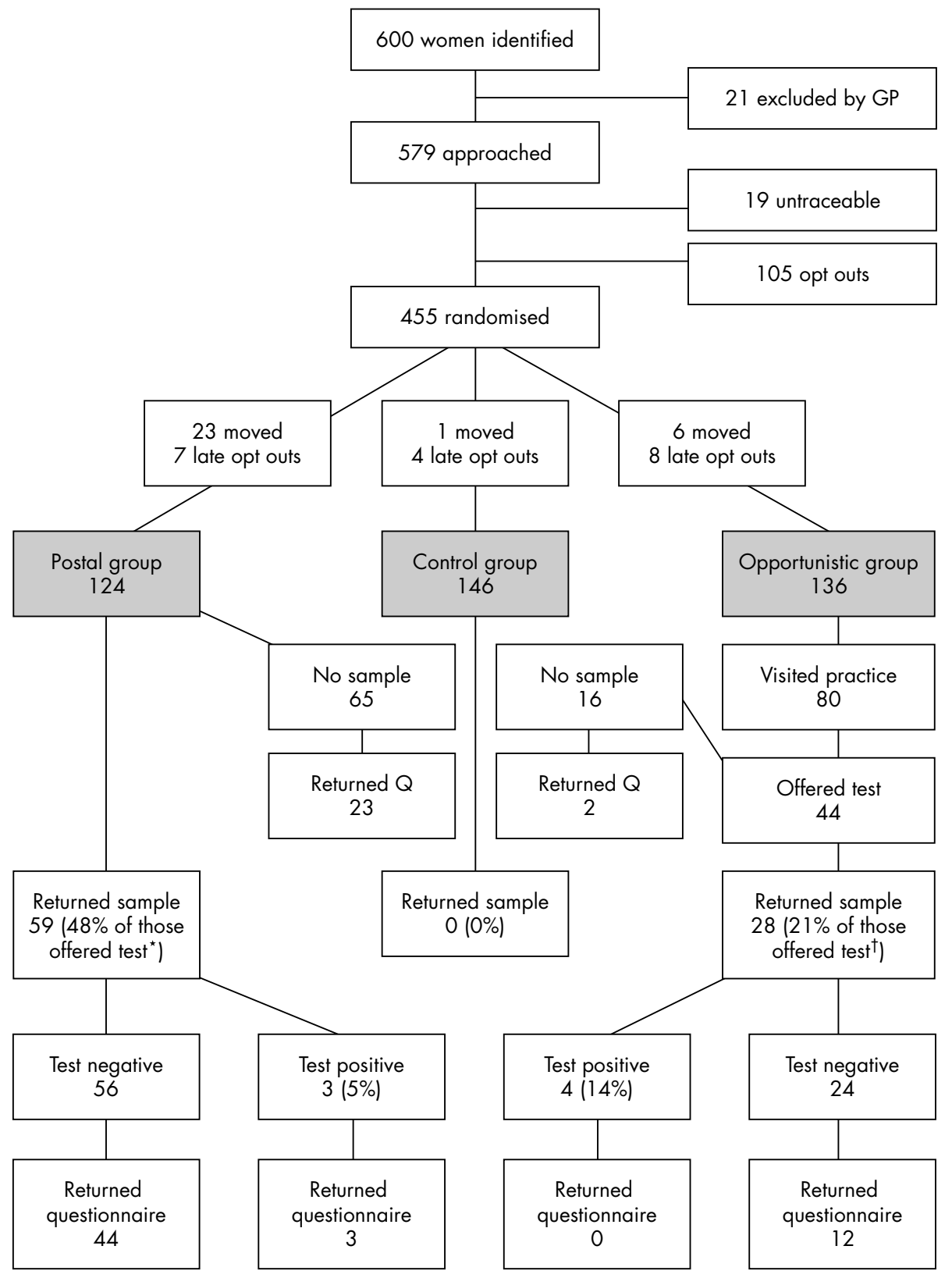

* $38 \%$ of women randomised to postal group; ${ }^{\dagger} 19 \%$ of women randomised to opportunistic group.

Figure 2 Participant numbers, study group allocation, screening uptake, and questionnaire response rates.

the patient's GP and sent to patients at different phases. The mailing date was recorded on a slip attached to each pack and returned to the study office.

Two hundred patients aged 16-30 years were selected from each practice list using the random sampling function in SPSS. Women deemed unsuitable for the trial (for example, those with terminal illness) were excluded by their GPs.

One month after the initial mailing to patients, opt out slips were collated and the study list was amended and anonymised by practice staff. The researcher used this anonymised list to allocate women randomly to one of three study groups: postal, opportunistic, or control.

\section{Postal group}

Women were sent pre-labelled test kits returnable to the laboratory in a reply paid, pre-addressed envelope; a chlamydia information leaflet and a consent form to be returned to the practice.

\section{Opportunistic group}

Before the screening phase, case notes of these women were flagged and identifier labels and a checklist for clinicians were placed inside the notes. These women were to be offered screening when they attended the practice for any service during the four month study period. Test kits were similar to those used for the postal group.

\section{Control group}

Women in the control group were treated according to usual practice.

On completion of the study period, practice nurses extracted data from medical records on all numbers and 


\begin{tabular}{llll}
\hline Table 1 & \multicolumn{3}{l|}{ Baseline characteristics of study groups } \\
\hline & Postal group & Opportunistic group & Control group \\
\hline Number & 124 & 146 & 136 \\
Age (mean (SD)) & $25.3(4.6)$ & $24.5(4.3)$ & $23.3(4.0)$ \\
Deprivation category & & 25 & 32 \\
$1-2$ & 28 & 58 & 48 \\
$3-5$ & 47 & 36 & 44 \\
$6-7$ & 34 & 17 & 22 \\
Missing & 15 & & \\
\hline
\end{tabular}

types of consultations in the study period and the preceding year, and on recorded consultations relating to sexual health during the whole period covered by their records.

\section{Staff interviews}

A sample of 13 staff (two GPs, one or two nurses, and one or two administrative staff from each practice) was interviewed by one of the authors (MR) to obtain views on the workload associated with postal and opportunistic screening and on the benefits and obstacles associated with the screening and research processes. The sampling strategy was designed to recruit staff who were directly involved in the rolling out of the research project, and this varied by practice. Interviews were transcribed and analysed thematically, by coding responses into categories and themes, and looking for negative cases.

\section{Statistical methods}

Data from practices and laboratories were recorded in Microsoft Access databases. Comparisons were made between practices and age groups $(<20,20-24$, and $>25$ years) using Fisher's exact test in SPSS.

Data from the opportunistic group were used to test whether women who visited their practice more often were more likely to be offered screening. Among attendees, the conditional probability of being offered screening and of accepting a test was estimated for the three age groups.

Attendance data from all women over the year before screening were used to estimate the probabilities of attending the practice during a full year in each age group. When combined with the conditional probabilities derived earlier, this permitted estimates of uptake rates in a study lasting for one year. Similarly, given the rate of positive chlamydia results among those screened in the opportunistic group, the rate of positive results for the whole population if the screening programme was to run over a full year was estimated.

\section{RESULTS}

Of the 221 practices approached, $146(66 \%)$ responded. Of these, $62(42 \%)$ responded positively, $23(16 \%)$ expressed interest without commitment, and 61 (42\%) declined. Data were collected successfully from the three participating practices.

\section{Uptake}

Figure 2 summarises participant numbers, study group allocation, screening uptake, and questionnaire response rates. Opt out rates did not vary significantly by practice or deprivation category. Younger patients in the two practices with adequate data were somewhat more likely to opt out: 29 of $91(32 \%)$ in the under-20 age group compared with 54 of $258(21 \%)$ among the over-20s $(\mathrm{p}=0.045)$.

The study groups were well matched for age and deprivation category (table 1).

There were no significant inter-practice differences in offers or uptake of postal or opportunistic screening.

There was no significant attrition in offers of screening to the opportunistic group over the study period as measured by date of first attendance at the practice. We found no association between the number of visits to the practice and the probability of being offered a test. Based on the consultation data for the previous year, we estimate that the overall uptake rate in the opportunistic group over one year would be about $30 \%$.

Most tests were offered by GPs (36 of 41 consultations where the clinician could be determined), mainly during consultations for non-gynaecological illnesses. One woman attended her GP requesting chlamydia screening. Three of the four offers by practice nurses occurred during consultations for cervical smears or contraception.

Women between 20 and 24 years were least likely to attend their practice ( 19 of 45 compared with 61 of 91: $\mathrm{p}=0.024$ ). Among those who did attend, women under 20 years were most likely to be offered a test ( 15 of 18 compared with 29 of 61: $p=0.0015)$. In the interviews some GPs associated the condition with a younger age group and reported a tendency to target younger women routinely.

In women under 20 years, uptake for opportunistic screening (9 of 15,60\%) was significantly higher than for postal screening $(5$ of $23,22 \%)(p=0.036)$. The opportunistic screening acceptance rate was not significantly higher when considered as a proportion of those randomised to opportunistic screening (9 of 27, 33\%) but, based on projections from consultation patterns in the preceding year, it would increase over a longer study period. In women over 20 years who were offered a test the opportunistic uptake rate (19 of 29,66\%) was not significantly higher than in the postal group (54 of $101,53 \%)(p=0.35)$. The overall uptake rate was nevertheless significantly lower in the opportunistic group (28 of

Table 2 Sample size calculation

\begin{tabular}{|c|c|c|c|}
\hline \multirow[b]{2}{*}{ Sample size required to detect difference in: } & \multicolumn{3}{|c|}{ number per group } \\
\hline & Age $16-19$ & Age 20-24 & Age $25-30$ \\
\hline $\begin{array}{l}\text { Uptake rate at } \alpha=5 \% \text { with } 90 \% \text { power, assuming true difference in } \\
\text { uptake rate to be } 50 \% \text { of that observed in feasibility study }\end{array}$ & 1241 & 1024 & 145 \\
\hline $\begin{array}{l}\text { Positive test rate at } \alpha=5 \% \text { with } 90 \% \text { power, assuming lower rate } \\
\text { group to be } 50 \% \text { of higher rate group }\end{array}$ & 736 & 708 & 2122 \\
\hline
\end{tabular}


Table 3 Questionnaire returns and patient acceptability

\begin{tabular}{|c|c|c|c|c|c|c|c|c|c|c|}
\hline & & Postal & Opportunistic & Rural & $\begin{array}{l}\text { Deprived } \\
\text { urban }\end{array}$ & $\begin{array}{l}\text { Affluent } \\
\text { urban }\end{array}$ & $\begin{array}{l}<20 \\
\text { years }\end{array}$ & $\begin{array}{l}20-24 \\
\text { years }\end{array}$ & $\begin{array}{l}25+ \\
\text { years }\end{array}$ & Total \\
\hline Questionnaires returned & Number/Total & $47 / 59$ & $12 / 28$ & $24 / 31$ & $15 / 27$ & $20 / 29$ & $7 / 14$ & $15 / 23$ & $37 / 50$ & $59 / 87$ \\
\hline $\begin{array}{l}\text { Questionnaires returned } \\
\text { (negative result) }\end{array}$ & Number/Total & $44 / 56$ & $11 / 24$ & $22 / 29$ & $13 / 24$ & $20 / 27$ & $6 / 12$ & $14 / 20$ & $35 / 48$ & $55 / 80$ \\
\hline $\begin{array}{l}\text { Questionnaires returned } \\
\text { (positive result) }\end{array}$ & Number/Total & $3 / 3$ & $1 / 4$ & $2 / 2$ & $2 / 3$ & $0 / 2$ & $1 / 2$ & $1 / 3$ & $2 / 2$ & $4 / 7$ \\
\hline Number (\%) who thought & Number & 43 & 11 & 23 & 12 & 19 & 5 & 14 & 35 & 54 \\
\hline approach was appropriate & \% Respondents & 91 & 92 & 96 & 80 & 95 & 71 & 93 & 95 & 92 \\
\hline Number $(\%)$ who thought & Number & 44 & 11 & 23 & 13 & 19 & 6 & 15 & 34 & 55 \\
\hline $\begin{array}{l}\text { information supplied was } \\
\text { adequate }\end{array}$ & \% Respondents & 94 & 92 & 96 & 87 & 95 & 86 & 100 & 92 & 92 \\
\hline
\end{tabular}

$136,21 \%$ ) compared with the postal group (59 of 124, $48 \%$ : $\mathrm{p}<0.0001$ ) in this short study period.

No woman in the control group was offered chlamydia testing during the screening phase. Comparisons of the control group with the other two intervention groups were therefore not performed.

\section{Sample size calculation}

Table 2 shows sample size calculations for a definitive trial of opportunistic compared with postal screening (in terms of uptake and positivity rates).

\section{Acceptability}

Questionnaires were sent to all 87 women who submitted specimens. Table 3 summarises the responses.

Fourteen of the 25 respondents who were offered testing but did not submit samples (56\%) either forgot about the request or lost the kit. Only two respondents $(8 \%)$ stated that they had not yet had sexual intercourse. Fifteen $(60 \%)$ considered the offer of testing appropriate, but seven (28\%) considered it inappropriate. Some 56 of 59 (95\%) respondents thought men should be offered screening.

\section{Women with positive test results}

All seven women who tested positive were requested to make an appointment to see the practice nurse. Nevertheless, one woman in the rural practice attended her GP and one pregnant patient in the deprived practice sought treatment from her obstetrician. Three of the five women seen by practice nurses returned completed questionnaires. All three felt comfortable and reassured during the consultation and all had notified sexual partners. The practice nurses reported that they had found the training course informative and relevant to their practice.

\section{Qualitative results from staff interviews}

The study was labour intensive and practice administrative staff reported problems with its management. Staff worked additional hours to ensure distribution of study materials and collation of responses:

\section{Key points}

- A randomised controlled trial comparing postal and opportunistic screening for chlamydial infection in general practice is feasible, although resource intensive.

- There may be problems with generalising from screening trials in which patients may opt out from the possibility of being offered screening.
"It's finding the time to be able to devote someone or several people to do what is required... we had almost everybody in one Saturday so it was useful just to really to discuss the various aspects as well but to also just go through the list and update because it takes you far longer when you're being interrupted" (administrator).

Difficulties were exacerbated during periods of short staffing.

Some problems related to specific screening strategies. For the postal group, test kits were bulky and staff had to deliver them to the local post office. This was especially problematic for the staff at the deprived practice, which had no local post office. There were anecdotal reports in this practice that test kits were tampered with and/or wrongly delivered:

"They don't always deliver (the mail), they don't always deliver very quickly or in the case of some of the kits they just deliver them straight back to the practice without any attempt to deliver them to the patients... We do have a lot of mail that goes missing and that is something that is probably not going to change" (Administrator).

One GP expressed concern that postal screening could create difficulties within the homes of recipients.

"The key concern was the mail shot going to someone, could be the daughter of strict parents or the wife of someone who is anxious about other relationships could cause a difficult situation for either of them" ${ }^{\prime \prime}(G P)$.

GPs also reported problems when offering opportunistic screening. These included difficulties in changing the focus of the consultation to chlamydia screening; feeling that it was inappropriate (especially if the consultation involved a mental health problem) and concerns about the time required to raise the issue of chlamydia:

"As far as the clinical side I just find it a bit stressful -'Oh there's another opportunity gone' and you know I've a busy surgery, and I've got to talk about this completely different subject and sometimes it may be relevant but more often than not its not been relevant...... and the girl has not been that keen" (GP).

The practice nurses were trained in management of confirmed chlamydial infection. They found the training had a broader value to them in their everyday practice and was beneficial. 
"It was very good, and the whole thing about contact tracing and giving people positive results and things like that, it made you think about it, it was very good...Information about when swabs should be at the lab in order to get good results, you know, things like that have impacted already on my practice" (practice nurse).

\section{DISCUSSION}

\section{Summary of main findings}

This feasibility study established that opportunities exist in general practice to conduct clinical trials of differing approaches to screening. Despite the high potential workload, almost two fifths of practices approached were interested in participation. Furthermore, the three participating practices showed a high level of commitment despite staffing shortages. Training sessions gave staff an understanding of the study but considerable support was required for the project to run smoothly.

Uptake of screening was $48 \%$ of the target population with a postal approach and $21 \%$ over four months with an opportunistic approach (38\% and 19\% respectively if the number of women randomised is used as denominator). The apparent superiority of postal screening in this broad comparison may obscure the fact that younger women, who are at highest risk for chlamydial infection, may respond better to opportunistic screening. In the interviews some GPs reported a tendency to target younger women in their routine practice, associating the condition with a younger age group. This finding suggests that these GPs, unlike others ${ }^{15}$ had become aware of the population risk profile, possibly resulting from participation in the study. The practice nurses were enthusiastic about taking on responsibilities for sexual health work, but, compared with the GPs, they had far fewer consultations with younger women.

\section{Strengths and limitations of the study}

The requirement to obtain consent before randomisation meant that participation was incomplete. It is difficult to extrapolate findings from the research project to the clinical situation in which all eligible patients would be offered screening. The three LRECs permitted us to use a design involving an initial pre-randomisation "opt out" approach

\section{Policy implications}

- The evidence base for chlamydia screening is not robust. Evaluation of screening strategies through randomised controlled trials is essential. Trials of population screening are only meaningful if prerandomisation opt out rates are minimal. Significant numbers of women opted out in our study despite the use of "opt out" (passive) consent.

- Cluster randomised trials of screening may be more likely to succeed than trials with individual randomisation. We consider random assignment to an offer of screening without consent and anonymised transmission of aggregate data from practices to researchers to be ethically sound.

- Screening for genital Chlamydia trachomatis in primary care is feasible, but potentially resource intensive. If population based screening was to be implemented, it is probable that optimal coverage would be achieved with a combination of postal and opportunistic screening. because randomisation to an offer of screening was considered a comparatively benign intervention. We were not able to establish what proportion of women who opted out did so because they had never been sexually active. In a definitive study there could be a case for asking sexually inactive women not to opt out for this reason, but to return an empty sample container if offered a test. This approach might nevertheless be considered by some as a form of indirect behavioural surveillance.

The design involved individual rather than cluster randomisation. This approach significantly increases statistical power, but it is more complicated for practices and runs the risk of introducing contamination of the study groups. The finding that none of the women in the usual care group was offered screening suggests that contamination was probably not an important problem. Nevertheless, awareness among clinicians and patients that they were participating in a trial may have artificially increased rates of offer and acceptance of screening. Alternatively, a universal, rather than experimental, opportunistic screening programme might be associated with a greater acceptability of testing and a higher proportion of women being offered screening as health professionals become more experienced. The fact that none of the control group was tested might indicate a potential adverse effect of a screening programme: a belief among healthcare providers that screening of asymptomatic individuals is sufficient.

Our study was based on women because opportunistic screening strategies have not been developed for the male population. They generally have comparatively mild clinical manifestations of chlamydia infection and are more likely than women to be infrequent attenders (31\% of men and $15 \%$ of women aged 16-30 had not attended their GP in the past year-Scottish Household Survey 1999/2000: authors' own analysis). This is not an argument against screening men. Successful screening programmes will depend in part on preventing re-infection by identifying and treating infected men, but it is probable that postal approaches will yield higher uptake rates among men. ${ }^{19}$

Although questionnaire responses generally supported the offer of testing, the response rate among women who did not return samples was low. Work in progress in Bristol and Birmingham will help to elucidate the attitudes of women declining tests (Rona Campbell, personal communication, July 2003).

\section{Comparison with existing literature}

The $48 \%$ uptake rate for postal tests obtained in our study is in keeping with data obtained in other European studies. $^{12131920}$ The 83\% uptake of postal screening among men and women aged 18-45 years in one practice ${ }^{21}$ was achieved only after intensive follow up of non-responders (John MacLeod, personal communication, April 2002).

We estimate that $30 \%$ of those offered opportunistic screening would be tested over a one year period. This figure lies below $49 \%$ screened in general practice in the Portsmouth study but is close to $24 \%$ screened in the Wirral ${ }^{11}$ and $22 \%$ in one practice in Yorkshire. ${ }^{22}$ It is possible that the high level of population coverage in the Portsmouth study results partly from payments to practices for each test conducted.

Although the numbers are small, the prevalence of chlamydial infection among those tested in the opportunistic group is higher than among the postal responders. This is not surprising given that the clinicians seem to have targeted women at higher risk. Our results parallel the higher prevalence levels obtained in the Portsmouth/Wirral opportunistic screening pilots compared with those in the Bristol/ Birmingham postal studies. 


\section{Implications for future research}

This was a very complex trial with a high level of involvement of practice staff in project management. In a larger trial, we recommend that identified practice staff members perform project work in protected (and reimbursed) time, rather than on an ad hoc basis. Increasing the number of clinical contacts between young women and practice nurses may improve recruitment and workload management. A cluster design, in which only one type of intervention would be offered by each practice, would simplify matters greatly and might give clearer results, but with loss of statistical power for a given sample size. A typical intra-cluster correlation coefficient of 0.1 for process variables in a trial of this type would inflate the necessary sample size approximately 21 times. ${ }^{23}$

The impact of UK data protection and European human rights legislation on the design of this project was highly significant. Research ethics committees in the UK may apply the legislative framework more vigorously than committees in other European nations. ${ }^{24}$ In our study, research staff were not able to examine any non-anonymised data without informed "opt in" consent, so a great deal of the project management work had to be conducted by practice staff. The alternative, obtaining opt in consent to be offered screening, would reduce participation rates and greatly reduce the value of any future trial.

Similar considerations now apply to all evaluations of population screening in primary care, with a serious risk that health service policy on screening will be based on inadequate evidence. We believe that when new screening technologies are introduced, there is a strong case for the conduct of cluster randomised trials without individual patient consent to the offer of screening. ${ }^{25}$

\section{ACKNOWLEDGEMENTS}

Thanks are due to Mrs Jean Taylor and Mrs Catherine McNeil who provided administrative support, and Mr Ian Howe in the Regional Virus Laboratory at Gartnavel Hospital, Glasgow. Dr Ahilya Noone of the Scottish Centre for Infection and Environmental Health participated in the early stages of the design of the project. Dr Bruce Armstrong, sexual health advisor at the Sandyford Initiative, Glasgow, helped in the design and delivery of the practice nurse training. We are grateful for the patience and determination of the staff in the three participating practices. Data from the Scottish Household Survey 1999/2000 were made available through the ESRC Data Archive, with the help of Mr Matt Sutton. The copyright holder, the original data producer, the relevant funding agencies, and the Data Archive bear no responsibility for their further analysis or interpretation. Finally, we would like to acknowledge our referees (Drs Cassell, Stephenson, and van Essen) for making suggestions that have helped us to improve the paper.

\section{Authors' affiliations}

A Senok, P Wilson, A McConnachie, B Fitzpatrick, General Practice and Primary Care, Division of Community Based Sciences, University of Glasgow, Glasgow, UK

M Reid, N Craig, Public Health and Health Policy, Division of Community Based Sciences, University of Glasgow

A Scoular, Greater Glasgow NHS Board, Glasgow, UK

A MacDonald, Bridgeton and Dennistoun LHCC, Bridgeton Health Centre, Glasgow, UK
Funding: this study was funded by the Scottish Executive Chief Scientist Office.

Competing interests: none declared.

The study protocol received approval from the following ethics committees: Greater Glasgow Primary Care Trust, Lanarkshire Primary Care Trust, and Forth Valley Primary Care Trust.

\section{REFERENCES}

1 Fenton K, Korovessis C, Johnson AM, et al. Sexual behaviour in Britain: reported sexually transmitted infections and prevalent genital Chlamydia trachomatis infection. Lancet 2001;358:1851-4.

2 Cates W, Wasserheit JM. Genital chlamydial infections: epidemiology and reproductive sequelae. Am J Obstet Gynecol 1991;164:1771-81.

3 Chernesky MA, Jang $D$, Lee $H$, et al. Diagnosis of Chlamydia trachomatis infections in men and women by testing first-void urine by ligase chain reaction. J Clin Microbiol 1994;32:2682-5.

4 Black CM. Current methods of laboratory diagnosis of Chlamydia trachomatis Infections. Clin Microbiol Rev 1997; 10:160-84.

5 CMOs Expert Advisory Group. Chlamydia in general practice. London: Department of Health, 1998.

6 Paavonen J, Puolakkainen M, Paukku M, et al. Cost-benefit analysis of first void urine Chlamydia trachomatis screening programme. Obstet Gynecol 1998; $92: 292-8$

7 Van Valkengoed IGM, Postma MJ, Morré SA, et al. Cost effectiveness analysis of a population based screening programme for asymptomatic Chlamydia trachomatis infections in women by means of home obtained urine specimens. Sex Transm Inf 2001;77:276-82.

8 Low N, Egger M. What should we do about screening for genital chlamydia? Int J Epidemiol 2002;31:891-3.

9 ClaSS Study Group. Evidence is not (yet) enough for evidence based policy on chlamydia screening. BMJ 2001;322:364.

10 SIGN. Management of genital chlamydia trachomatis infection. Edinburgh: Scottish Intercollegiate Guidelines Network, 2000.

11 Pimenta JM, Catchpole M, Rogers PA, et al. Opportunistic screening for genital chlamydial infection. I: Acceptability of urine testing in primary and secondary healthcare settings, Sex Transm Infect 2003;79:16-21.

12 Østergaard L, Andersen B, Olesen F, et al. Efficacy of home sampling for screening of Chlamydia trachomatis: randomised study. BMJ 1998:317:26-7.

13 vanValkengoed IGM, Boeke AJP, van den Brule AJC, et al. Systematische opsporing van infecties met Chlamydia trachomatis bij mannen en vrouwen zonder klachten in de huisartspraktijk me behulp van per post verstuurde urinemonsters. Ned Tijdschr Geneeskd 1999;143:672-6.

14 Kinn S, MacNaughton J, Noone A, et al. Chlamydia trachomatis in primary care: knowledge and practice in Glasgow. Br J Gen Pract 2000;50:214-15.

15 Armstrong B, Kinn S, Scoular A, et al. Shared care in the management of genital Chlamydia trachomatis infection in primary care. Sex Transm Infect 2003;79:369-71.

16 Carstairs V, Morris R. Deprivation and health in Scotland. Aberdeen: Aberdeen University Press, 1991.

17 McLoone P. Carstairs scores for Scottish postcode sectors from the 1991 census. Glasgow: Public Health Research Unit, University of Glasgow, 1994.

18 Santer M, Warner P, Wyke S, et al. Opportunistic screening for chlamydia infection in general practice: can we reach young women? J Med Screen 2000;7:175-6.

19 Andersen B, Olesen F, Møller JK, et al. Population-based strategies for outreach screening of urogenital Chlamydia trachomatis infections: a randomized, controlled trial. J Infect Dis 2002;185:252-8.

20 Stephenson J, Carder C, Copas A, et al. Home screening for genital chlamydia infection: is it acceptable to young men and women? Sex Transm Infect 2000;76:25-7.

21 Macleod J, Rowsell R, Horner P, et al. Postal urine specimens: are they a feasible method for genital chlamydia infection screening. Br J Gen Pract 1999;49:455-8.

22 Tobin C, Aggarwal R, Clarke J, et al. Chlamydia trachomatis: opportunistic screening in primary care. Br J Gen Pract 2001;51:565-6.

23 Campbell M, Grimshaw J, Steen N. Sample size calculations for cluster randomised trials. Changing Professional Practice in Europe Group (EU BIOMED II Concerted Action). J Health Serv Res Policy 2000;5:12-16.

24 Hearnshaw $\mathrm{H}$. Comparison of requirements of research ethics committees in 11 European countries for a non-invasive interventional study. BMJ 2004;328:140-1.

25 Cassell J, Young A. Why we should not seek individual informed consent for participation in health services research. J Med Ethics 2002;28:313-17. 